REVIEW

\title{
Antiviral-resistant hepatitis B virus: can we prevent this monster from growing?
}

\author{
F. Zoulim, ${ }^{1,2,3}$ M. Buti ${ }^{4}$ and A. S. Lok $^{5}$ \\ ${ }^{1}$ INSERM, U871, 69003 Lyon, France; ${ }^{2}$ Université Lyon 1, IFR62 Lyon-Est, 69008 Lyon, France; ${ }^{3}$ Hospices Civils de Lyon, Hôtel Dieu, Department \\ of Liver Diseases, 69002 Lyon, France; ${ }^{4}$ Hospital General Universitario Valle de Hebron, Barcelona, Spain; and ${ }^{5}$ Division of Gastroenterology, University \\ of Michigan, Ann Arbor, MI, USA
}

Received July 2007; accepted for publication August 2007

SUMMARY. Despite the recent progress in antiviral therapy of chronic hepatitis $\mathrm{B}$, clinical experience has shown that antiviral drug resistance is inevitable with the administration of nucleoside analog monotherapy. The long-term persistence of the viral genome in infected cells and the high rate of spontaneous mutation is the basis for the selection of HBV mutants that are resistant to polymerase inhibitors. Selection of antiviral-resistant mutations leads to a rise in viral load and progression of liver disease. The incidence of antiviral resistance depends on the potency and genetic barrier to resistance of the antiviral drug, highlighting the importance of the choice if first line therapy. The determination of cross-resistance profile of each drug has allowed the design of rescue therapy for patients with virologic breakthrough. Early diagnosis and treatment intervention allow the majority of patients to maintain in clinical remission despite the occurrence of drug resistance. Clinical studies are ongoing to determine the best strategy to prevent or delay antiviral drug resistance and of its impact on liver disease.

Keywords: antiviral drugs, antiviral therapy, chronic hepatitis, drug resistance, hepatitis B virus, viral genome variability.

\section{INTRODUCTION}

Despite the development of new nucleoside analogues that effectively inhibits hepatitis B virus (HBV) replication, antiviral therapy of chronic hepatitis B remains a clinical challenge mainly because of the slow kinetics of viral clearance and the subsequent emergence of drug-resistant mutants [1]. In this manuscript, we review the clinical impact of drug resistance, the new concepts of viral resistance management based on genotypic and phenotypic analysis of $\mathrm{HBV}$ drug-resistant mutants and measures to prevent antiviral-resistant $\mathrm{HBV}$.

Nucleoside analogues mainly target the different viral polymerase activities, i.e. RNA-dependent DNA synthesis (reverse transcription) and DNA-dependent DNA synthesis [1]. This results in the inhibition of infectious virion production and a decreased rate of infection of new hepatocytes. However, none of the available polymerase inhibitors have

Abbreviations: HBV, hepatitis B virus; $\mathrm{HBeAg}$, hepatitis B e antigen; HIV, human immunodeficiency virus.

Correspondence: Fabien Zoulim, INSERM U271, 151 cours Albert Thomas, 69424 Lyon cedex 03, France. E-mail: zoulim@lyon. inserm.fr been shown to prevent infection of uninfected hepatocytes and the de novo formation of covalently closed circular (ccc) DNA [2]. Antivirals have a modest indirect effect on cccDNA by inhibiting the intracellular recycling of nucleocapsids, but the long half-life of infected hepatocytes and cccDNA necessitates very long duration of therapy placing patients at risk of developing drug resistance $[1,3]$.

\section{HOW DO ANTIVIRAL-RESISTANT HEPATITIS B VIRUS MUTANTS ARISE?}

Hepatitis B virus is a DNA virus that replicates via reverse transcription of pregenomic RNA. Unlike DNA polymerase, reverse transcriptase does not have proofreading ability. Therefore, HBV has a higher error rate than other DNA viruses. The high error rate and the large amount of virions produced $\left(10^{12}-10^{13} /\right.$ day $)$ mean that every possible mutation is generated daily [4]. Because of the overlapping open reading frames, many of the spontaneous mutations may be detrimental to the virus and would not be propagated. Nevertheless, some spontaneously occurring mutations may persist and antiviral-resistant HBV mutants may be generated spontaneously before exposure to nucleos(t)ide analogue treatment [5]. 
Antiviral-resistant HBV mutants are selected in the presence of antiviral therapy because they can replicate better than wild-type virus in the presence of antiviral drug. Various factors are associated with an increased likelihood of antiviral-resistant mutant selection. Patients with high pretreatment HBV DNA levels, those with slow or inadequate viral suppression, and those who had resistance to prior treatment that are cross-resistant to the current therapy are at increased risk of developing antiviral resistance [6,7]. The likelihood of antiviral resistance is higher if the treatment has intermediate antiviral activity (enough to exert selective pressure on the virus but not enough to result in rapid suppression of HBV replication) and a low genetic barrier to resistance (marked decrease in susceptibility because of a single amino acid substitution not affecting viral genome replication capacity). Host factors that contribute to an increased likelihood of antiviral resistance include noncompliance with medications, immunosuppression (resulting in enhanced replication by loss of immune control of infected cells) [8], abundant replication space (large number of uninfected hepatocytes as in the newly transplanted liver) [9] and possibly polymorphisms in kinases responsible for converting prodrugs to active drugs or for phosphorylation of nucleos(t)ide analogues to the active triphosphates.

\section{DEFINITION OF HEPATITIS B VIRUS DRUG RESISTANCE}

Clinically, HBV drug resistance manifests at different levels [10,11]: (i) genotypic resistance corresponds to the detection of mutation(s) in the HBV genome which have been found to be selected during antiviral therapy and to confer resistance to the antiviral agent; i.e. the detection of specific $\mathrm{HBV}$ polymerase gene mutations; (ii) virologic breakthrough corresponds to a confirmed increase (two consecutive occasions) in serum HBV DNA levels by $>1 \log _{10}$ copies $/ \mathrm{mL}$ during therapy, compared with nadir, in a medication compliant patient; (iii) biochemical breakthrough is defined as an increase in serum aminotransferase levels that accompanies a virologic breakthrough. In most patients, these three levels of drug resistance present successively with intervals of months or years. However, progression from genotypic resistance to biochemical breakthrough can be abrupt particularly in patients who are immunosuppressed or have underlying cirrhosis.

Another situation of treatment failure is a suboptimal treatment response and primary nonresponse. The definition is still debated but there is some agreement to define it by the inability of antiviral treatment to reduce serum HBV DNA by $\geq 2 \log _{10} \mathrm{IU} / \mathrm{mL}$ and to a level $<4 \log _{10} \mathrm{IU} / \mathrm{mL}$ after the first 6 months of therapy. This phenomenon is likely to be due to pharmacologic issue including the pharmacodynamics of the drug and its antiviral potency as well as patient's compliance. Recently, it was suggested that virological factors may be involved as pre-existing mutations, i.e. rtI233V, were associated with primary nonresponse to adefovir in three patients [12].

Cross-resistance is defined as a mutation(s) that confers resistance to more than one antiviral drug by in vitro testing. This usually translates into failure of the other drugs as rescue therapy in the clinical setting. The knowledge of cross-resistance is therefore critical in developing treatment

\begin{tabular}{|c|c|c|c|c|}
\hline & \multicolumn{4}{|l|}{ Resistance mutation } \\
\hline & $\begin{array}{l}\mathrm{L} 180 \mathrm{M}+\mathrm{M} 204 \mathrm{~V} \\
\mathrm{M} 204 \mathrm{I}\end{array}$ & $\mathrm{N} 236 \mathrm{~T}$ & A181V & $\begin{array}{l}\mathrm{S} 202 \mathrm{G} / \mathrm{I}^{*} \\
\mathrm{M}^{2} 50 \mathrm{I}^{*}\end{array}$ \\
\hline $\begin{array}{l}\text { Drugs with } \\
\text { reduced activity }\end{array}$ & $\begin{array}{l}\text { Lamivudine } \\
\text { Lamivudine } \\
\text { Entecavir } \\
\text { Telbivudine } \\
\text { Emtricitabine } \\
\text { Emtricitabine } \\
\text { Clevudine } \\
\text { Entecavir } \\
\text { Telbivudine } \\
\text { Elvucitabine }\end{array}$ & $\begin{array}{l}\text { Adefovir } \\
\text { Tenofovir }\end{array}$ & $\begin{array}{l}\text { Adefovir } \\
\text { Lamivudine }\end{array}$ & $\begin{array}{l}\text { Entecavir } \\
\text { Lamivudine } \\
\text { Telbivudine }\end{array}$ \\
\hline $\begin{array}{l}\text { Drugs that } \\
\text { remain active }\end{array}$ & $\begin{array}{l}\text { Adefovir } \\
\text { Tenofovir }\end{array}$ & $\begin{array}{l}\text { Lamivudine } \\
\text { Emtricitabine } \\
\text { Entecavir } \\
\text { Telbivudine }\end{array}$ & $\begin{array}{l}\text { Tenofovir } \\
\text { Entecavir }\end{array}$ & $\begin{array}{l}\text { Adefovir } \\
\text { Tenofovir }\end{array}$ \\
\hline
\end{tabular}

Table 1 Results of in vitro cross-resistance analysis

Results were obtained after in vitro phenotypic analysis of the resistant mutants $[15,17-19,21,22,38]$.

*In the presence of primary resistance mutations (L180M + M204V). 
strategies after treatment failure to the first antiviral drug. The results of cross-resistance analysis for the most common HBV antiviral-resistant mutants are summarized in Table 1.

\section{PHENOTYPIC ASSAYS}

Phenotypic assays are crucial in confirming if HBV polymerase mutations observed during antiviral therapy confer resistance to the drug and to determine if those mutations have cross-resistance to other drugs. Several assays has been used to determine the in vitro phenotype of antiviral-resistant mutants and have been reviewed recently [13]: (i) sitedirected mutagenesis of laboratory strains cloned in appropriate vectors and transient transfection of hepatoma cell lines; (ii) exchange of polymerase gene fragments between HBV genomes from clinical isolates and the laboratory strain; (iii) subcloning of the whole HBV polymerase gene; (iv) amplification of the whole HBV genome and its transfection in hepatoma cell lines, either directly or after a cloning step; (v) cloning of 1.1 unit length HBV genome from clinical isolates and their transfection in cell lines. In each case, viral genome replication capacity is determined in the presence or absence of drugs. Other approaches have been used such as the cloning of HBV mutants in recombinant baculovirus vectors and the transduction of hepatoma cell lines by these baculoviruses.

Phenotypic assays are tedious but they have been instrumental in characterizing the mutations that confer resistance to lamivudine, adefovir, entecavir and telbivudine; the susceptibility of these mutants to other antiviral agents; and the differentiation between primary resistant mutations and secondary compensatory mutations [14-20]. Phenotypic assays have demonstrated that combination of antiviral drugs does not adequately suppress multi-drug-resistant mutants selected after sequential monotherapies [21,22].

Another important aspect of phenotypic assays is the assessment of replication fitness of the drug-resistant mutants, i.e. their capacity to spread in the liver and outgrow wild type virus [9]. The principle relies on the production of $\mathrm{HBV}$ mutants and the inoculation of susceptible cells, i.e. primary human or Tupaia hepatocytes andor the highly differentiated HepaRG cell line [13]. However, the number of infected cells and virus production in these systems are low. Another approach is to inoculate humanized chimeric mice with these mutants to study their infectivity in vivo [23]. These assays to study viral fitness are being improved to provide new insight in the selection process of the HBV drug-resistant mutants.

\section{DIAGNOSIS OF HEPATITIS B VIRUS DRUG RESISTANCE}

Direct sequencing is the most convenient method for identifying resistance mutations to new treatments. However, direct sequencing is insensitive. Whereas direct sequencing can detect mutants that constitute $10-20 \%$ of the virus population, studies in patients with human immunodeficiency virus (HIV) infection who have received highly active antiretroviral treatment have shown that resistant mutants are not consistently detected unless they constitute $\geq 40 \%$ of the virus population. For nucleos(t)ide analogues with well-characterized resistance mutations, more sensitive methods that can consistently detect mutants when present in $\geq 10 \%$ of the virus population should be used [24]. These more sensitive methods permit earlier detection of resistance mutants, prior to biochemical breakthrough $[25,26]$. Recent studies showed that institution of rescue therapy at this early stage is more effective. Early detection of antiviral resistance is particularly important for patients with cirrhosis and in liver transplant recipients. Restriction fragment length polymorphism and reverse hybridization using strips coated with oligonucleotide probes (line probes) are the most common methods used for detecting antiviralresistant HBV mutations. They are simple and can provide results within 1 day; however, they can only detect previously characterized mutations, and adaptation of these methods to detect mutants that confer resistance to a growing list of nucleos(t)ide analogues will be challenging [27].

\section{INCIDENCE OF ANTIVIRAL-RESISTANT HEPATITIS B VIRUS}

Although antiviral-resistant $\mathrm{HBV}$ mutations can occur spontaneously, these mutants are present as a minor virus species $(<0.1 \%)$ in a large pool of viruses in most HBV carriers who have not been exposed to nucleos(t)ide analogues. Thus, unless ultra-sensitive assays are used to selectively amplify the mutants, antiviral-resistant HBV cannot be detected in patients who have not received nucleos $(\mathrm{t})$ ide analogue treatment [5]. Among patients receiving a specific nucleos(t)ide analogue, the frequency of detection of antiviral-resistant $\mathrm{HBV}$ mutants correlates with pretreatment serum HBV DNA level, rapidity of viral suppression and duration of treatment [7,28-30]. The incidence of genotypic resistance also varies with the sensitivity of the methods used for the detection of resistant mutations and the patient population being studied.

Clinical studies of antiviral resistance have varied from testing all patients with detectable HBV DNA by polymerase chain reaction to only patients with confirmed virologic breakthrough, those with viral rebound (increase in HBV DNA to $>5 \log$ copies $\mathrm{mL}$ ), and those with biochemical breakthrough. The latter approaches result in underestimation of the rate of genotypic resistance, particularly if this is coupled with the use of an insensitive method for detection of antiviral-resistant mutation such as direct sequencing. These differences in methodology make it difficult to compare the incidence of genotypic resistance to various HBV therapies 
across clinical trials. Variations in patient characteristics (such as pretreatment HBV DNA level, prior treatment and liver transplantation) further confound these comparisons, emphasizing the need for standardized definitions and assays for viral resistance.

\section{CLINICAL IMPACT OF HEPATITIS B VIRUS DRUG RESISTANCE}

The emergence of antiviral-resistant strains of HBV leads to viral, and subsequently biochemical breakthrough, negating any benefits achieved during initial antiviral treatment. The clinical outcome for patients with antiviral resistance is related to their age, the severity of the underlying liver disease and the intensity of the hepatitis flare. One study investigated the use of lamivudine for a period of up to 6 years in nearly 1000 patients found that the proportion of patients who experienced hepatitis flares increased from $33 \%$ for those with lamivudine-resistant HBV for 1 year to $77 \%$ for those who had lamivudine-resistant HBV for more than 4 years [30]. Furthermore, hepatic decompensation occurred in only $0-2 \%$ of patients with lamivudine resistance during the first 4 years, but thereafter the risk of developing hepatic decompensation increased to $6 \%$. The favourable outcome in this study could be related to the relatively young age of the patients (mean: 32 years) and the fact that most patients had early-stage liver disease (only 10\% had cirrhosis) [30]. Another study examined the efficacy of lamivudine vs placebo in the prevention of disease progression for patients with advanced liver fibrosis/cirrhosis [31]. After a median of 32 months, $49 \%$ of the patients in the lamivudine-treated group had genotypic resistance. The Child-Pugh scores were more likely to be increased in these patients than in those without lamivudine-resistant mutants $(7 \%$ vs $<1 \%, P<0.001)$. Eight of the 14 deaths in the lamivudine-treated group were related to emergence of lamivudine resistance [31]. Despite these complications, patients with lamivudine resistance were less likely to develop progressive liver disease than the placebotreated patients indicating a clinical benefit of lamivudine therapy, during the study period.

However, there have been many reports that emergence of lamivudine resistance was associated with severe hepatitis flare, liver failure and death, especially in older patients and those with cirrhosis or immunosuppression $[26,30,32]$. Several studies have also demonstrated that histologic improvements achieved during the first year of treatment are negated with the development of lamivudine resistance. In one study, patients underwent liver biopsies at baseline, year 1 and year 3. Among the patients with lamivudine resistance for more than 2 years, the proportion of patients with reduction in necroinflammation decreased from $56 \%$ at year 1 to $36 \%$ at year 3 , and progression to bridging fibrosis was observed in approximately $27 \%$ of patients. By contrast, $83 \%$ of the patients

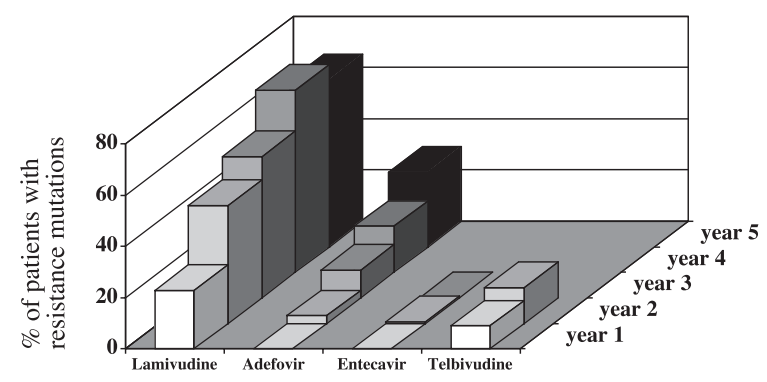

Fig. 1 Incidence of genotypic resistance in nucleoside naïve patients. Results were obtained from clinical studies $[5,7,29,30,34,45]$. For entecavir, Lamivudine resistance mutations are considered as primary entecavir resistance mutations.

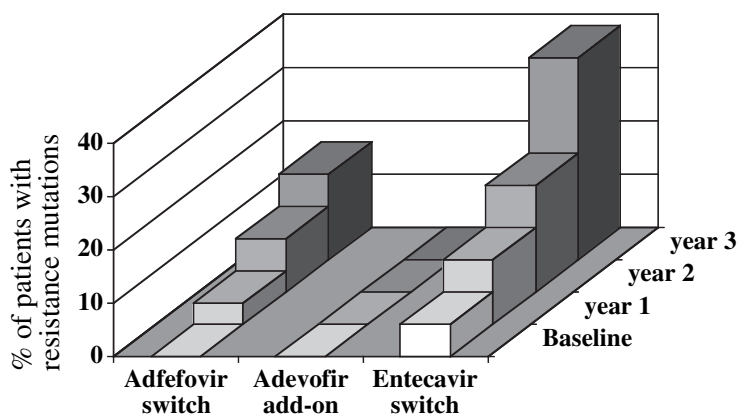

Fig. 2 Incidence of genotypic resistance in lamivudineresistant patients. Results of selected studies are presented $[35,42]$.

without lamivudine resistance experienced a reduction of liver fibrosis in the same period [33].

Patients who develop lamivudine resistance are less likely to undergo hepatitis B e antigen (HBeAg) seroconversion. One study of 58 patients found that after 4-5 years of continued lamivudine therapy, $\mathrm{HBeAg}$ seroconversion was achieved in $38 \%$ of those with and $75-80 \%$ of those without lamivudine resistance mutations [7].

Most of the data on the clinical impact of antiviral-resistant HBV have been derived from studies of lamivudine therapy. Limited data indicate that resistance to other antiviral drugs such as adefovir is associated with the same consequences: viral rebound, hepatitis flares and rarely liver failure [34]. The rate of resistance to adefovir dipivoxil and to entecavir is lower than that to lamivudine in nucleosidenaïve patients [5,34] (Fig. 1). However, in lamivudineexperienced patients, the risk of resistance to adefovir dipivoxil (when prescribed in monotherapy) or to entecavir increases significantly [6,35,36] (Fig. 2).

Implementation of combination prophylaxis of nucleos(t)ide analogues and hepatitis B immune globulin has decreased HBV recurrence postliver transplant to less than $10 \%$. Currently, antiviral-resistant HBV is the main cause of HBV recurrence, accounting for over $90 \%$ of recurrent HBV postliver transplant [37]. 
Another consequence of the development of antiviralresistant $\mathrm{HBV}$ is the presence of mutations that confer crossresistance with other nucleos(t)ide analogues that are approved or currently under development, limiting future treatment options. This is of particular concern in young patients. Switching from one treatment to another may result in the selection of multi-drug-resistant mutations, especially if sequential monotherapy is used. Recent data indicate that multi-drug-resistant mutations collocate in the same HBV genome and are refractory to combination therapy $[21,38,39]$. Thus, patients may eventually run out of treatment options.

Finally, a potential concern is the transmission of antiviral-resistant $\mathrm{HBV}$ and de novo infection with these resistant strains [40]. Although antiviral-resistant HBV mutants are supposed to have decreased replication fitness compared with wild-type HBV and are expected to be outgrown by wild-type $\mathrm{HBV}$ in a nucleos(t)ide analogue-naïve host, transmission is possible and vigilance is necessary.

\section{PREVENTION OF ANTIVIRAL-RESISTANT HEPATITIS B VIRUS}

As with other areas of medicine, prevention is better than treatment. Judicious use of nucleos(t)ide analogues in patients with chronic hepatitis $\mathrm{B}$ is the most effective prophylaxis against the development of antiviral-resistant HBV. Thus, patients with minimal disease (such as inactive carriers) and those who are unlikely to achieve sustained response (such as $\mathrm{HBeAg}$-positive patients in the immune tolerant phase) should not be treated with nucleos(t)ide analogues, particularly if they are young ( $<30$ years of age). When possible, the most potent nucleos(t)ide analogue with the lowest rate of genotypic resistance should be administered and compliance reinforced. Although combination therapy has been shown to prevent antiviral resistance in patients with HIV infection, the promise of combination therapy has not yet been fulfilled for patients with HBV infection. Sequential therapy with drugs that are crossresistant will lead to stepwise selection of strains harbouring increasing number of polymerase gene mutations conferring resistance to the first drug and then to both medications, as in the case of entecavir therapy for patients with lamivudineresistant HBV. Thus, the benefits of antiviral treatment must be balanced against the risk of drug resistance during longterm treatment. Studies combining drugs with high genetic barriers to resistance and no cross resistance should be conducted to determine the optimal combination therapy for hepatitis B.

\section{MANAGEMENT OF PATIENTS WITH ANTIVIRAL- RESISTANT HEPATITIS B VIRUS (FIG. 3)}

Hepatitis B patients receiving antiviral therapy should be closely monitored for virologic breakthroughs. Recent studies indicate that initiating rescue therapy early, at the time of virologic breakthrough, is more effective than delaying until the patients have developed biochemical breakthrough [41].

Patients with lamivudine resistance can be managed by switching to adefovir or by adding adefovir. Several studies found that addition of adefovir is associated with a lower risk of subsequent adefovir resistance. This is confirmed in a large multicentre Italian cohort study involving $588 \mathrm{HBeAg-}$ negative patients who had developed lamivudine resistance and in whom treatment with adefovir was initiated either in combination with or as a substitution for lamivudine. Over a period of up to 36 months, $11 \%$ of patients switched to adefovir monotherapy developed genotypic resistance to adefovir, compared with none of the patients who received add-on adefovir. Similarly, virologic breakthrough was only
Fig. 3 Recommendations for the management of hepatitis B virus drug resistance. Resistance rate of selected studies are presented $[6,35,36,42]$. Recommendations are based on the results of phenotypic analysis and clinical studies.
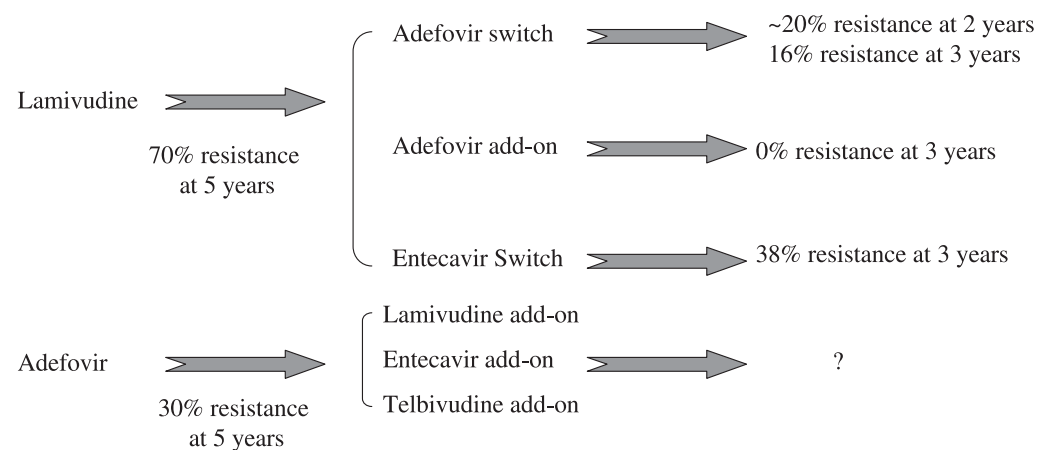

at 5 years

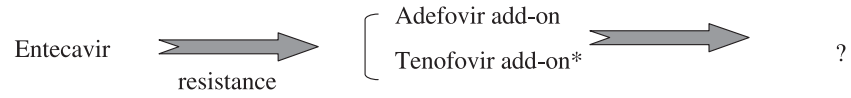

at 5 years?

Telbivudine

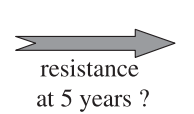

CAdefovir add-on

Tenofovir add-on*

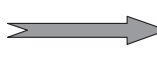

* Not yet approved for HBV therapy 
seen in $5 \%$ of the add-on group vs $24 \%$ in the monotherapy group [42].

Patients with lamivudine resistance can also be managed with entecavir. However, despite the use of a higher dose, virologic rebound because of entecavir resistance was observed in $9 \%$ and $17 \%$ after 2 and 3 years of entecavir treatment [35]. Given our current understanding that preexisting lamivudine-resistant mutations predisposes to further selection of mutations at 169, 184, 202 and 250 that confer resistance to entecavir $[17,38,39]$, entecavir is not an optimal treatment for patients with lamivudine resistance.

Patients with adefovir resistance should be managed according to the cross-resistance profile of the mutant selected by adefovir. In vitro data of phenotypic assays show that the rtN236T mutation is susceptible to lamivudine and entecavir $[15,18,22]$. The rtA $181 \mathrm{~V}$ mutation confers a decreased susceptibility to lamivudine but remains sensitive to entecavir [21]. A few reports of clinical cases confirm that these patients should be managed according to the profile of resistance mutations $[6,21,43]$.

To date, very few cases of entecavir resistance among nucleoside-naïve patients who have received entecavir treatment have been reported. The in vitro characterization of the entecavir-resistant strains showed that they are also resistant to lamivudine, but remain sensitive to adefovir and tenofovir. A recent report confirmed the initial efficacy of adefovir in decreasing serum HBV DNA level in a patient with entecavir-resistant mutants [38].

Several studies found that the risk of selection of drugresistant mutants increases significantly when serum HBV DNA does not decline below $3 \log _{10}$ copies $\mathrm{mL}$ after 6 months of lamivudine or telbivudine therapy [28,44], or after 12 months of adefovir dipivoxil therapy [34]. These data suggest that treatment should be adapted early, in patients with partial virologic response to prevent the subsequent selection of resistant viruses.

\section{CONCLUSION}

Hepatitis B virus circulates as a pool of heterogenous viral genomes and its mutants are archived in the cccDNA; thus, HBV drug resistance is bound to occur with nucleoside analogue monotherapy. With the development of new nucleoside analogues that exhibit more potent antiviral activity and a lower rate of viral resistance, phenotypic analysis and cross-resistance data will be important for the adaptation of antiviral therapy in patients with drug resistance as well as for the design of combination trials with longterm end-points. HBV drug resistance is becoming a major clinical challenge in patients receiving long-term antiviral therapy. As many patients have now been exposed to several courses of antiviral drugs, the risk of selection of multi-drugresistant mutants is increasingly common. Based on clinical experience and on results of detailed genotypic and phenotypic analysis, management of patients with drug-resistant
HBV is evolving towards earlier add-on therapy. The availability of several antiviral drugs with different resistance patterns and excellent safety profiles offers a unique opportunity for the evaluation of de novo combination therapy or early add-on therapy to prevent drug resistance.

\section{ACKNOWLEDGEMENTS}

F. Zoulim receives grant from INSERM and the European Community (VIRGIL Network of Excellence, grant LSHMCT-2004-503359). A. S. Lok is partially funded by an NIH grant U01 DK57577. M. Buti receives grant from the European Community (VIRGIL Network of Excellence, grant LSHM-CT-2004-503359 and CIBER-Hepad).

\section{CONFLICTS OF INTEREST}

FZ serves as a consultant for Gilead and Idenix. ASL serves as a consultant and receives research support from Gilead, BMS, GSK, and Idenix. MB has declared no conflicts of interest.

\section{REFERENCES}

1 Zoulim F. Mechanism of viral persistence and resistance to nucleoside and nucleotide analogs in chronic hepatitis B virus infection. Antiviral Res 2004; 64: 1-15.

2 Delmas J, Schorr O, Jamard C et al. Inhibitory effect of adefovir on viral DNA synthesis and covalently closed circular DNA formation in duck hepatitis B virus-infected hepatocytes in vivo and in vitro. Antimicrob Agents Chemother 2002; 46: 425-433.

3 Werle-Lapostolle B, Bowden S, Locarnini S et al. Persistence of cccDNA during the natural history of chronic hepatitis B and decline during adefovir dipivoxil therapy. Gastroenterology 2004; 126: 1750-1758.

4 Gunther S, Fischer L, Pult I, Sterneck M, Will H. Naturally occurring variants of hepatitis B virus. Adv Virus Res 1999; 52: 25-137.

5 Colonno RJ, Rose R, Baldick CJ et al. Entecavir resistance is rare in nucleoside naïve patients with hepatitis B. Hepatology 2006; 44: 1656-1665.

6 Fung SK, Chae HB, Fontana RJ et al. Virologic response and resistance to adefovir in patients with chronic hepatitis $\mathrm{B}$. J Hepatol 2006; 44: 283-290.

7 Lai CL, Dienstag J, Schiff E et al. Prevalence and clinical correlates of YMDD variants during lamivudine therapy for patients with chronic hepatitis B. Clin Infect Dis 2003; 36: 687-696.

8 Benhamou Y, Bochet M, Thibault V et al. Long-term incidence of hepatitis B virus resistance to lamivudine in human immunodeficiency virus-infected patients. Hepatology 1999; 30: 1302-1306.

9 Litwin S, Toll E, Jilbert AR, Mason WS. The competing roles of virus replication and hepatocyte death rates in the emergence of drug-resistant mutants: theoretical considerations. J Clin Virol 2005; 34(Suppl. 1): S96-S107. 
10 Locarnini S, Hatzakis A, Heathcote J et al. Management of antiviral resistance in patients with chronic hepatitis B. Antivir Ther 2004; 9: 679-693.

11 Zoulim F. Antiviral therapy of chronic hepatitis B. Antiviral Res 2006; 71: 206-215.

12 Schildgen O, Sirma H, Funk A et al. Variant of hepatitis B virus with primary resistance to adefovir. $N$ Engl J Med 2006; 354: 1807-1812.

13 Zoulim F. In vitro models for studying hepatitis B virus drug resistance. Semin Liver Dis 2006; 26: 171-180.

14 Allen MI, Deslauriers M, Andrews CW et al. Lamivudine Clinical Investigation Group. Identification and characterization of mutations in hepatitis B virus resistant to lamivudine. Hepatology 1998; 27: 1670-1677.

15 Angus P, Vaughan R, Xiong S et al. Resistance to adefovir dipivoxil therapy associated with the selection of a novel mutation in the HBV polymerase. Gastroenterology 2003; 125: 292-297.

16 Durantel D, Carrouee-Durantel S, Werle-Lapostolle B et al. A new strategy for studying in vitro the drug susceptibility of clinical isolates of human hepatitis B virus. Hepatology 2004; 40: 855-864.

17 Tenney DJ, Levine SM, Rose RE et al. Clinical emergence of entecavir-resistant hepatitis B virus requires additional substitutions in virus already resistant to Lamivudine. Antimicrob Agents Chemother 2004; 48: 3498-3507.

18 Villeneuve JP, Durantel D, Durantel S et al. Selection of a hepatitis B virus strain resistant to adefovir in a liver transplantation patient. J Hepatol 2003; 39: 1085-1089.

19 Yang H, Qi X, Sabogal A, Miller M, Xiong S, Delaney WE 4th. Cross-resistance testing of next-generation nucleoside and nucleotide analogues against lamivudine-resistant HBV. Antivir Ther 2005; 10: 625-633.

20 Delaney WE 4th, Yang H, Westland CE et al. The hepatitis B virus polymerase mutation rtV173L is selected during lamivudine therapy and enhances viral replication in vitro. J Virol 2003; 77: 11833-11841.

21 Villet S, Pichoud C, Villeneuve JP, Trepo C, Zoulim F. Selection of a multiple drug-resistant hepatitis B virus strain in a liver-transplanted patient. Gastroenterology 2006; 131: 1253-1261.

22 Brunelle MN, Jacquard AC, Pichoud C et al. Susceptibility to antivirals of a human HBV strain with mutations conferring resistance to both lamivudine and adefovir. Hepatology 2005; 41: 1391-1398.

23 Dandri M, Lutgehetmann M, Volz T, Petersen J. Small animal model systems for studying hepatitis B virus replication and pathogenesis. Semin Liver Dis 2006; 26: 181191.

24 Stuyver L, van Geyt C, De Gendt S et al. Line probe assay for monitoring drug resistance in hepatitis B virus-infected patients during antiviral therapy. J Clin Microbiol 2000; 38 : 702-707.

25 Lok AS, Zoulim F, Locarnini S et al. Monitoring drug resistance in chronic hepatitis B virus (HBV)-infected patients during lamivudine therapy: evaluation of performance of INNO-LiPA HBV DR assay. J Clin Microbiol 2002; 40: 3729 3734 .
26 Nafa S, Ahmed S, Tavan D et al. Early detection of viral resistance by determination of hepatitis $\mathrm{B}$ virus polymerase mutations in patients treated by lamivudine for chronic hepatitis B. Hepatology 2000; 32: 1078-1088.

27 Zoulim F. New nucleic acid diagnostic tests in viral hepatitis. Semin Liver Dis 2006; 26: 309-317.

28 Yuen MF, Sablon E, Hui CK, Yuan HJ, Decraemer H, Lai CL. Factors associated with hepatitis B virus DNA breakthrough in patients receiving prolonged lamivudine therapy. Нераtology 2001; 34: 785-791.

29 Zoulim F, Poynard T, Degos F et al. A prospective study of the evolution of lamivudine resistance mutations in patients with chronic hepatitis B treated with lamivudine. J Viral Hepat 2006; 13: 278-288.

30 Lok AS, Lai CL, Leung $\mathrm{N}$ et al. Long-term safety of lamivudine treatment in patients with chronic hepatitis B. Gastroenterology 2003; 125: 1714-1722.

31 Liaw YF, Sung JJ, Chow WC et al. Lamivudine for patients with chronic hepatitis B and advanced liver disease. N Engl J Med 2004; 351: 1521-1531.

32 Hadziyannis SJ, Papatheodoridis GV, Dimou E, Laras A, Papaioannou C. Efficacy of long-term lamivudine monotherapy in patients with hepatitis B e antigen-negative chronic hepatitis B. Hepatology 2000; 32: 847-851.

33 Dienstag JL, Goldin RD, Heathcote EJ et al. Histological outcome during long-term lamivudine therapy. Gastroenterology 2003; 124: 105-117.

34 Hadziyannis SJ, Tassopoulos NC, Heathcote EJ et al. Longterm therapy with adefovir dipivoxil for HBeAg-negative chronic hepatitis B for up to 5 years. Gastroenterology 2006; 131: 1743-1751.

35 Sherman M, Yurdaydin C, Sollano J et al. Entecavir for treatment of lamivudine-refractory, HBeAg-positive chronic hepatitis B. Gastroenterology 2006; 130: 20392049.

36 Lee YS, Suh DJ, Lim YS et al. Increased risk of adefovir resistance in patients with lamivudine-resistant chronic hepatitis B after 48 weeks of adefovir dipivoxil monotherapy. Hepatology 2006; 43: 1385-1391.

37 Schreibman IR, Schiff ER. Prevention and treatment of recurrent hepatitis B after liver transplantation: the current role of nucleoside and nucleotide analogues. Ann Clin Microbiol Antimicrob 2006; 5: 8.

38 Villet S, Ollivet A, Pichoud C et al. Stepwise process for the development of entecavir resistance in a chronic hepatitis B virus infected patient. J Hepatol 2007; 46: 531-538.

39 Yim HJ, Hussain M, Liu Y, Wong SN, Fung SK, Lok AS. Evolution of multi-drug resistant hepatitis B virus during sequential therapy. Hepatology 2006; 44: 703-712.

40 Thibault V, Aubron-Olivier C, Agut H, Katlama C. Primary infection with a lamivudine-resistant hepatitis B virus. Aids 2002; 16: 131-133.

41 Lampertico P, Vigano M, Manenti E, Iavarone M, Lunghi G, Colombo M. Adefovir rapidly suppresses hepatitis B in HBeAg-negative patients developing genotypic resistance to lamivudine. Hepatology 2005; 42: 1414-1419.

42 Lampertico P, Marzano A, Levrero $M$ et al. Adefovir and lamivudine combination therapy is superior to adefovir monotherapy for lamivudine-resistant patients with 
HBeAg-negative chronic hepatitis B. Hepatology 2006; 44: Abstract LB5, p693A.

43 Fung SK, Andreone P, Han SH et al. Adefovir-resistant hepatitis B can be associated with viral rebound and hepatic decompensation. J Hepatol 2005; 43: 937-943.

44 Di Bisceglie AM, Lai CL, Gane E et al. Telbivudine globe trial: maximal early $\mathrm{HBV}$ suppression is predic- tive of optimal two-year efficacy in nucleoside-treated hepatitis B patients. Hepatology 2006; 44: Abstract 112, p230A.

45 Lai CL, Leung N, Teo EK et al. A 1-year trial of telbivudine, lamivudine, and the combination in patients with hepatitis B e antigen-positive chronic hepatitis B. Gastroenterology 2005; 129: 528-536. 